\title{
Unusual cardiac tamponade
}

Received: 19 January 2013

Accepted: 19 January 2013

Published online: 22 February 2013

(C) Springer-Verlag Berlin Heidelberg and ESICM 2013

J. M. R. Meijer (®) · D. W. de Lange

Division of Anesthesiology, Intensive Care and Emergency Medicine, Department Intensive Care, University Medical

Center Utrecht, Utrecht, The Netherlands

e-mail: jmrmeijer@planet.nl; J.M.R.Meijer-7@umcutrecht.nl

A 69-year-old woman with adult polycystic kidney disease (APCKD) presented herself at our emergency department. A diagnosis of community-acquired pneumonia was made. She was treated with antibiotics, but oxygenation deteriorated quickly and she needed mechanical ventilation. From that moment onwards, she needed massive fluid infusions and enormous amounts of norepinephrine to maintain cardiac output and blood pressure. This was much more than expected from septic shock. Transthoracic cardiac ultrasound showed a compressed right atrium and an almost collapsed inferior vena cava. A CT scan showed the culprit (Fig. 1, arrows): a large liver cyst compressed the heart, pushing it into the left hemithorax. Ultrasound-guided drainage withdrew $6,100 \mathrm{ml}$ from the cyst in $1 \mathrm{~h}$. Thereafter, the need for fluid transfusions and norepinephrine vanished completely. Sadly she developed a refractory shock due to Enterococcus faecium sepsis of this cyst and died.

Conflicts of interest None.

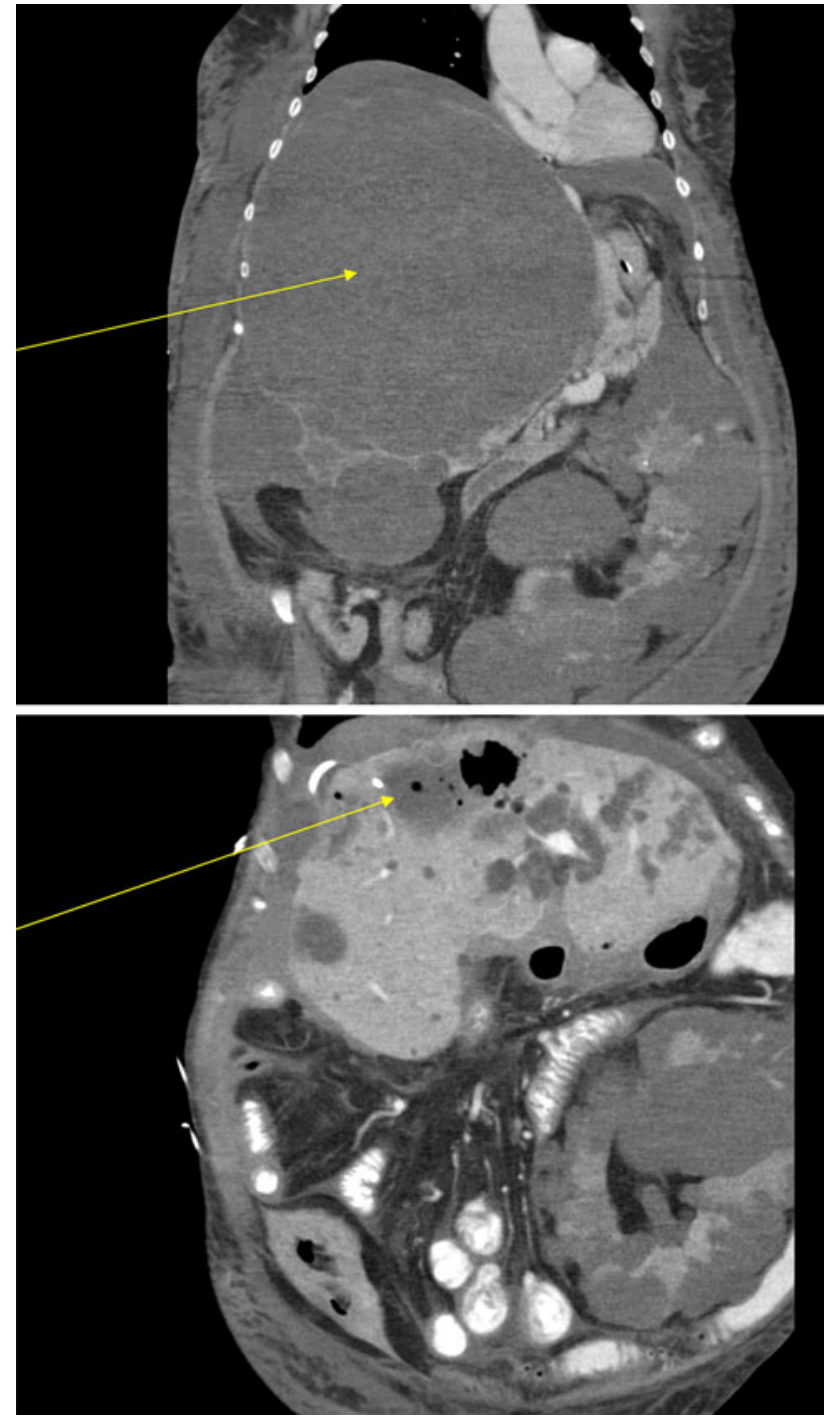

Fig. 1 Liver cyst before and after drainage (arrows) 